Article

\title{
Digital Gap in Universities and Challenges for Quality Education: A Diagnostic Study in Mexico and Spain
}

\author{
Guillermo Rodríguez-Abitia ${ }^{1}$, Sandra Martínez-Pérez ${ }^{2} \mathbb{}$, , Maria Soledad Ramirez-Montoya ${ }^{3}$ \\ and Edgar Lopez-Caudana $4, *$ (i) \\ 1 General Direction of Computing and Information and Communications Technologies, Universidad Nacional \\ Autónoma de México, 58089 Mexico City, Mexico; grdrz@unam.mx \\ 2 Department of Didactics and Educational Organization, Faculty of Education, University of Barcelona, \\ 08035 Barcelona, Spain; smartinezperez@ub.edu \\ 3 Tecnologico de Monterrey, School of Humanities and Education, 64849 Monterrey, Mexico; \\ solramirez@tec.mx \\ 4 Tecnologico de Monterrey, School of Engineering and Sciences, 14380 Mexico City, Mexico \\ * Correspondence: edlopez@tec.mx
}

Received: 1 October 2020; Accepted: 26 October 2020; Published: 31 October 2020

\begin{abstract}
The United Nations (UN) identifies four key elements as agents for change and for addressing societal challenges: education, research, innovation and leadership. The use of technology, from a pedagogical and organizational point of view, in higher education institutions has brought about new challenges. The integration of them in the teaching-learning processes has experienced a great evolution, giving way to a digital transformation and the acquisition of new skills and knowledge, thus pointing towards quality education within the framework of sustainable development objectives. This document aims to describe and analyze the ways in which seven higher education institutions, three in Spain and four in Mexico, have taken up the challenge of adopting technologies and applying them to the educational process. To this end, in-depth interviews and direct observations were carried out. The results point to three dimensions: technological, pedagogical and organizational, which shed light on the different factors that influence the choice and availability of the use of technologies. The results indicate that contextual factors play a determinant role in the ability of an institution to profit from technologies to aid the educational process and guarantee its quality.
\end{abstract}

Keywords: digital gap; higher education; ICT; education quality; SDG; educational innovation

\section{Introduction}

Technological advances have led to a major digital transformation. The process of integration and use of technologies in educational institutions has been complex and has been accompanied by great changes, according to the singularities of each context. Factors such as training, digital teaching skills, student knowledge and abilities, accessibility, infrastructure and educational policies, among other aspects, mark the investment and incorporation of information and communication technologies (ICTs), in these organizations. Despite the progress made, everything points to the education objectives not being met by 2030. The Sustainable Development Goals (SDGs) cover a wide range of possibilities and complex social, educational, economic and environmental challenges [1]. None of them make specific reference to ICT, although they do recognize the importance of the diffusion of ICTs in reducing the digital gap and developing knowledge societies. SDG framework includes seven ICT indicators covering six targets of goals 4 (ensure inclusive and equitable quality education and promote lifelong learning opportunities for all), 5 (achieve gender equality and empower all women and 
girls), 9 (build resilient infrastructure, promote inclusive and sustainable industrialization and foster innovation) and 17 (strengthen the means of implementation and revitalize the Global Partnership for Sustainable Development). Focusing on Objective 4, it identifies three key points: 4.4: proportion of youth/adults with ICT skills, by type of skills; 4.a.1.b.: proportion of schools with access to the Internet for pedagogical purposes; and 4.a.1.c.: proportion of schools with access to computers for pedagogical purposes [2]. According to the UN, there are four key elements to help society meet these challenges: education, research, innovation and leadership [3]. Universities, as the social fabric, play a fundamental role in achieving the strategic objectives of sustainable development in general and quality education in particular.

In order to promote a transformative change based on a new development model, it is necessary for the academic community to encourage other ways of learning, of understanding training and of interacting and living with technologies. Both professionals and students need to acquire certain digital and social skills in order to become agents of change in which, through higher education based on sustainable development, they can apply ICT to promote learning [4]. Therefore, it is essential to: (a) engage on the path towards the effective use of ICT, in line with the educational objectives and strategies of the institutions; (b) create scenarios in which ICT can be used in the teaching and learning processes.

Our aim is to describe and analyze the ways in which seven higher education institutions, three in Spain and four in Mexico, have taken up the challenge of adopting ICTs and applying them to the educational process, in order to shed light on the different factors that influence the choice and availability of the use of ICTs for quality, sustainable and equitable education. To this end, we present the background that guided our research and describe our multi-stage methodology, as well as a description of the tools developed and how the data were analyzed.

In addition, we present the interpretation and discussion of the results of the data collected, providing the possible implications of the use of ICT in higher education institutions, with the purpose of shedding light on the differences in ICT application and leverage for education, based on contextual ones. Finally, we address the limitations of the study and suggest directions for future research.

\section{Theoretical Background}

Education plays an important role in the growth, inclusion and innovation of a society. It promotes active, self-regulating, empathetic, flexible and critical thinking citizenship [5]. A society, known as the Society 5.0, is focused on people whose aim is to use technologies to create a better future, with changes in mentality, economy and geopolitics [6]. A "super-intelligent" society, which, as Keidanren describes [5], requires social evolution, and ethical implications and acceptance by all concerned. In order to do this, the current system needs to break down certain walls: (a) that of the administrations, with national strategies based on the Internet of Things and a "think tank" function; (b) the legal system, in which administrative digitalization is promoted; (c) that of technologies, a constant search for the formation of the "knowledge foundation", cybersecurity, emerging technologies and the existence of a commitment to research and development; and (d) that of human resources, as with educational reforms and digital transformations, it is necessary to provide and expand human resources with digital skills that lead us to quality education.

COVID-19 has altered our lifestyles and changed the way we understand education. Advances in technology (artificial intelligence, robotics, the Internet of Things, cloud computing, etc.) are giving rise to a digital transformation in the way we live, relate, work, train and learn, centred on Education 4.0 , the result of the fourth industrial revolution $[7,8]$. These advances are also having an impact on the acquisition of skills and knowledge-in formal, non-formal and informal education-in three major areas, as indicated by the LifeComp competency framework [9]: personal, social and learning to learn. Therefore, technologies are playing an increasingly important role in the various areas of life, making competences rapidly obsolete, and leading people to acquire new, more flexible and lifelong learning competences; at the same time, this invites us to update the existing ones. These digital 
technologies, in turn, are also seen as a means of: facilitating and improving learning; facing new challenges and opportunities; and learning to learn throughout life, individually and in society [10,11].

All of these transformations were already reflected in the 2020 Horizon Report [12]. In it, we find five major trends that mark the way in which the context itself is conceived: social, technological, economic, higher education and political. These trends combine in four scenarios that shape the teaching-learning processes: growth, limitation, collapse and transformation [12]. If we focus on the binomial higher education and technology, under the social, economic and political parameters, we can see that the use of technology continues to be more technical and curriculum centred, rather than practical and critical; it is seen as a catalyst for professional development to facilitate the use of technology in pedagogy [13]. To break with this theoretical-technical position, it is important that institutions consider three essential axes: the technological, the pedagogical and the organizational. Each of these is related to a perspective on how technologies are conceived: the technological one with information and communication technologies (ICTs), the pedagogical one linked to learning, digital competences, educational innovation and knowledge technologies (LKTs), and the organizational one with organizational and collaborative management technologies (OCTs) $[14,15]$. The combination of the three axes with their respective perspectives gives way to the use of technologies from an approach of empowerment and participation (EPT) (Figure 1), which allows us to face complex life situations and to develop competences that help us to successfully manage all the challenges that arise [16].

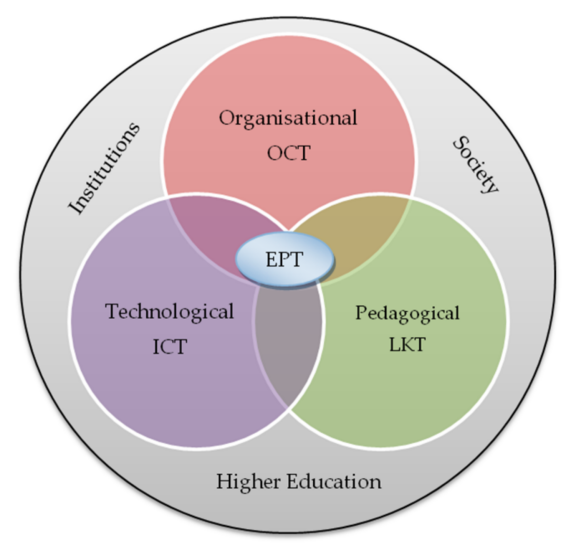

Figure 1. Dimensions in digital higher education.

This socio-educational overview leads us to look at educational digital agendas, specifically those of Europe and Latin America, as they are the objects of our study. These agendas are committed to offering quality, excellent and equitable education for all, with the right to adequate training and constant updating and to offering new opportunities and social challenges: flexibility, creativity, innovation, digital competences and improvement in learning processes [17-20]. To this end, different action plans have been drawn up, consisting of three guiding principles with their corresponding measures:

(a) Improving the use of digital technologies in the teaching and learning processes: better Wi-Fi connections in schools, use of self-assessment tools and digitally certified diplomas.

(b) Acquiring and developing digital skills to support the digital transformation: creation of a platform in higher institutions to improve teaching-learning processes; development of scientific digital skills_-open science; cyber security in education; and training in digital skills and entrepreneurship.

(c) Improving education systems on the basis of research, innovation and good practices that help to build a digital culture (digital literacy, digital competences, inclusion and citizenship).

On the basis of these actions, teachers must acquire the digital skills necessary not only for their personal lives but also for their professional lives in order to be able to participate in the present 
digital society, which increasingly requires specific skills necessary for innovation in teaching and learning [21]. For this reason, universities, as scenarios in the socio-educational network for the creation and dissemination of knowledge, are fundamental not only for social-digital transformation, but also for the achievement of the Sustainable Development Goals (SDGs). These institutions are perceived as an opportunity to provide future generations with the knowledge and skills necessary to face the different global challenges [22]. To this end, Agenda 2030 calls for a radical change, and changing curricula and changing education are essential elements to produce knowledge in line with current and future changes and challenges and to establish the basis for a fair, inclusive and egalitarian digital society [23]. Therefore, on the one hand, a "new" pedagogy is required that provides students with key competences: systemic and critical thinking, anticipation, regulation, strategy, transdisciplinary collaboration, creativity, self-awareness and problem solving [24,25], because "becoming digitally competent is essential if young people are to be able to participate effectively in a digitalized society and economy; not addressing these skills risks exacerbating the digital divide and perpetuating existing inequalities" [26] (p. 38). On the other hand, there is a need for operational policies and an integrative and interdisciplinary approach to sustainability development at the university level [27,28].

\section{Materials and Methods}

Our research was based on direct observations and in-depth interviews of key players at seven universities, with three from Spain and four from Mexico. A Spain-Mexico comparison is valuable to contrast two national contexts that, in spite of sharing common cultural values and background, differ greatly both in their level of socio-economic development and in the size of the digital gap. The selection of universities was also made to reflect the current higher education composition and situation for each of the countries. In Spain, public higher education is the main player, relegating the level of impact of private universities to a minimum. For that reason, it was decided to include one very large university and two mid-sized ones with different orientations. In the case of Mexico, private education accounts for one fourth of enrolment. Thus, three public institutions and one private institution were chosen. Variability amongst the public ones was provided by choosing them according to different geographical locations and sizes.

An observation and interview guide was adapted from a previously developed one [29] to capture all relevant information of the use and practise of information, organizational and learning technologies. The interview guide included 30 open questions, divided into six sections: institutional planning, institutional usage of ICTs, institutional programs for ICT usage, faculty digital skills and ICT usage, students' digital skills and educational resources. Since they were semi-structured, it was possible to deviate from the guide to explore further a particular element during the discussion, when considered important by the interviewer. The interviews were recorded and transcribed, and the information provided was verified by direct onsite observations, and codified afterwards according to certain pre-defined parameters of interpretation that allowed for suitable classification of the information collected. The observations were classified in one of five possible categories:

- Information and communication technology appropriation strategic commitment.

- Information and communication technology infrastructure access.

- Digital skills building for faculty.

- Learning and knowledge technology integration in the curricula.

- Organization and collaboration technology appropriation.

The first two categories were intended to measure the level of inclusion of an ICT strategy in the strategic plan of the universities under study, including a suitable allotment of resources for its execution, and the real digital inclusion realized. The third and fourth categories were intended to measure the level of readiness that an institution reached to successfully apply learning and communication technologies in the teaching and learning processes. Lastly, the fifth category was created to reflect how well the use of information technologies is applied to fully enrich the educational 
process by adding collaborative functions, as well as proper organizational functionalities to manage collaborative learning. These three dimensions involve an evolutionary process, where initial stages are to some extent requirements for the next ones, until an ideal state of technology leverage is attained.

A rubric was then applied to determine the level to which each university had made progress in each one of the three technological dimensions, as indicators of their path towards complete digital transformation.

Finally, a three-dimensional dispersion chart was drawn to graphically observe the positioning of each of the universities to facilitate comparisons amongst cases, and these were developed to draw our final conclusions.

\section{Results}

We now describe the results for each of the components of our methodology.

\subsection{Definition of Dimensions and Their Components}

From the above-described adapted instrument [29], a series of indicators was selected to reflect the nature of each of the dimensions in the rubric, as described below.

\subsubsection{Information and Communications Technologies (ICTs)}

To capture the level of ICT strategic commitment and access, indicators included the presence of a plan to include technology in both academic and administrative activities, along with appropriate performance measures. The existence of an organizational unit, responsible for the integration of ICTs in the teaching process, followed an established plan, or at least some initiatives for that purpose. The presence and scope of online education was also considered. As for access, aspects like wireless and wired connectivity, classroom equipment availability, spaces for the use and borrowing of computers by faculty and students, ICT services and support and provision activities were included.

\subsubsection{Learning and Knowledge Technologies (LKTs)}

With regard to LKT appropriation and readiness, it was first important to look for mechanisms in place to develop digital skills in faculty, such as formal training programs and domain diagnostics, coordinated and supported by a particular organizational unit with that purpose. It was also observed whether there was support for the basic use of learning management systems, and a complementary offer of blended and online education options. Finally, it was important to evaluate how extensively the use of LKT was intentionally included in the curricula of the programs in each institution.

\subsubsection{Organization and Collaboration Technologies (OCTs)}

For the last dimension, OCT appropriation, the focus was on more sophisticated use of learning management systems, so that they would not only be containers of content for a particular class, but actual tools for the students and faculty members to collaborate in knowledge building activities, with appropriate management for tasks ranging from assignments and evaluation to profile identification and learning personalization. Additionally, other initiatives related to the development of open educational resources by faculty members and their display in institutional repositories were assessed. For this dimension, it was also important to identify an official organizational unit in charge of making these initiatives happen.

\subsection{Field Study}

Universities were classified into four size categories: small (up to 5000 students), medium (between 5001 and 10,000 students), large (from 10,001 to 50,000 students) and very large (more than 50,000 students). For the purpose of this study, only three categories were included to better observe contrasting features. Table 1 shows the characteristics of the universities chosen for the study. As mentioned before, it was 
intended that the higher education environments were correctly represented based on their nature in each country. Three Spanish and four Mexican universities were included.

Table 1. Universities included in the study.

\begin{tabular}{ccccc}
\hline University & Community/State & Country & Size & Funding \\
\hline Spanish University 1 (SU1) & Cataluña & Spain & Very large & Public \\
Spanish University 2 (SU2) & Madrid & Spain & Large & Public \\
Spanish University 3 (SU3) & Madrid & Spain & Large & Public \\
Mexican University 1 (MU1) & México City & Mexico & Very large & Public \\
Mexican University 2 (MU2) & Chiapas & Mexico & Large & Public \\
Mexican University 3 (MU3) & Quintana Roo & Mexico & Small & Public \\
Mexican University 4 (MU4) & Nuevo Leon & Mexico & Very large & Private \\
\hline
\end{tabular}

After performing the site visit and in-depth interviews with key players (at least the person responsible for ICT services, the person in charge of the academic planning, one faculty member and the person responsible for faculty development), a rubric was applied to determine the level of maturity for each on the categories and dimensions in the study. The rubric was based on five levels: absent, incipient, medium, integrated and consolidated. We now discuss the results for each university.

\subsubsection{Spanish University 1}

With more than 65,000 students, SU1 is one of the leading educational institutions in Spain. It follows the general guidelines that the government of Cataluña has provided for all higher education institutions, where the level of digitization of services is comprehensive, and there are several organizational units that directly affect the ICT strategy in the university: the Institute of Education Sciences, the Center for Learning and Research Resources, a Department of Infrastructure and the Inter-University Group for Teachers' Formation. Together, they guarantee the access to ICT infrastructure, as well as to a Moodle-based virtual campus and appropriate mentoring for the academic application of ICTs. There is connectivity in all areas of the different campuses, and all classrooms are well equipped. Software licensing is regular and standardized, and provided freely to all community members.

Faculty training is offered in face-to-face, hybrid and online modalities, and it is based on the needs of each academic unit within the university to cover didactics, specialized software tools and the use of ICTs for education, including informational skills. The university also offers special degrees for new faculty, and the application of ICTs in the classroom is followed up. The university creates an instance in Moodle for each class, but usage is voluntary for professors. The learning management system (LMS) application is divided into three categories according to its aim: regular classes, faculty training and continued education. On the downside, professors use the LMS tools as closed content repositories, and they do not provide digital skills for faculty nor students, for the most part.

Professors share best practices in the application of ICTs for education through a web portal made for that purpose. Additionally, they have repositories for LKT tools, as well as banks of images, educational video channels, massive open online courses (MOOCs) and teaching and research content that may aid faculty in creating educational resources, which can be published in the university's repository, and then shared with the rest of Cataluña. Collaboration is fostered and supported.

\subsubsection{Spanish University 2}

The use of an LMS at this 20,000-student university is not mandatory, since they perceive themselves as a face-to-face university. They have promoted its use with moderate success to overcome resistance to change. Access to computers and appropriate connectivity is not a concern, since infrastructure is appropriate. It is normal for all students and faculty have their own computers and they prefer to use 
them than those of the university. The university provides IT support and a video recording studio. Videoconferencing facilities are available but not frequently used.

As in SU1, there is an Institute for Education Science, in charge of providing professors with courses to learn about the use of ICTs for their classes, and didactics in general. This is done by faculty members who are assigned work hours to train and help with LMS spaces. Course offerings are published each month, and complemented with materials in the form of videos and tutorials. There is a program for faculty innovation where projects are presented and approved on an individual basis, though with a limited budget. The main LMS is Blackboard, used at different levels by $80 \%$ of the faculty. Integration of ICTs in the curriculum is limited to one subject, common to all programs, but it is believed that it does not provide all the skills needed by the students.

Despite the apparent broad use of the LMS and the ample provision of software tools, there is no measure of the level of sophistication to which faculty and students engage in collaborative learning and work flows through technology. It is clear, however, that all academic services are well integrated with technology to help the organizational needs for academic management.

\subsubsection{Spanish University 3}

This multi-campus 20,000-student university differs from SU2 with regard to its approach to technology for education, as it commonly leads projects related to that matter in an association called the Spanish Universities Rectors' Conference. The importance is given to technology well beyond access and sufficient infrastructure. Since 2011, the university has counted on a specific organizational unit to promote educational innovation mediated by technology, as well as be in charge of the strategy for faculty training and the development of educational resources. For the latter, they encourage professors to get involved and provide help through what they call pedagogic coordinators. The use of Moodle is mandatory, at least as a content repository and grade reporting tool. The university provides appropriate connectivity and computer infrastructure, as well as videoconferencing support. The purchase of hardware and software is centralized and properly regulated.

The university provides professors with tools to develop courses and repositories for them, and for supplementary content. It also provides support for video recording, production and post-production, so that elaborate material can be obtained, beyond simply recording a lesson, and focusing on short and attractive ones. There is a teacher formation plan that seeks to take advantage of the fact that their faculty body is quite young on average. Yet, this has not been completely implemented.

The university encourages collaboration through cloud services and tools, sharing documents and spaces for interaction. It also integrates academic platforms in a very comprehensive way for administrative processes, so that work can be quite transparent for professors. As an added value, the university provides an analytics service to professors for all their classes, so that they can better adjust their methods.

\subsubsection{Mexican University 1}

The Institutional Development Plan of the main university in Mexico recognizes the urgent need to integrate ICTs into the educational processes to help better serve its 360,000 students. This plan aims at increasing the coverage and quality of data centers, networking and cloud services. Additionally, it targets the development of digital skills, and the university's readiness for blended and online learning models. This need became crucial as a result of the negative impact of the COVID-19 pandemic. This brought consequences even for its organizational structure, where areas were combined to better approach the educational innovation needs. The computer and networking infrastructure is extensive, but far from enough. As opposed to universities in Spain, a great majority of the community members do not possess a computer for their exclusive use, or suitable connectivity at home. Software licenses are negotiated centrally, and they are offered freely to students and professors.

Digital skills are formed in professors by many programs and organizational instances. Most of them are general programs and are not dedicated exclusively to ICT matters. Nonetheless, there is one 
that is, diagnosing the level of ICT domain both for students and professors, and providing the latter with a series of courses to meet their needs. They also offer mentoring and didactic help. Even though taking courses is mandatory for faculty members, this is not exclusive for ICT skills, so not everybody chooses to follow this course path. Most academic programs include at least one course related to ICTs, but integration as part of the learning process is normally absent.

There is more than one LMS platform at the university. Moodle is the most common one, and its use has spread, but normally just to store content and assign a few activities. Videoconferencing tools are also available for faculty members. However, the intention of capitalizing on technology for collaboration in academic life is relegated to some isolated initiatives. Additionally, administrative and academic processes are highly unintegrated. This is made worse by the high level of autonomy that each academic unit holds. Thus, trying to standardize services and technologies is quite a difficult task.

\subsubsection{Mexican University 2}

This 20,000-student university, the main one in its state, has a strategic plan that recognizes ICTs as horizontal and cross-sectional catalysts for attaining organizational objectives, providing some stimuli for faculty work and training in this subject matter. There have been some strong efforts to provide appropriate computer and connectivity infrastructure to the whole of the university community, but there is still considerable work to do. Home access is even more complicated than for MU1, due to its location in one of the most economically depressed states of the country, and the highly rural and multi-ethnic composition of its population. Infrastructure improvement projects are generally limited by restricted budgets.

There have been some efforts to develop digital and didactic skills in the faculty, but with limited results. Courses are generally offered for didactics, which then incorporate some ICT content. The university provides support for Moodle, and it is partially used by faculty, though there is a fully online modality in the academic offering.

Regardless of the flaws, the university uses technologies to collaborate on curriculum design and revisions, and it supports faculty in the use of video tutorials, microprocessors, transmedia narratives and other alternatives for course innovation. Administrative processes have a limited degree of integration through technology.

\subsubsection{Mexican University 3}

This small and fairly recently created university, serving close to 4000 students, has a development plan that recognizes the strategic role of ICTs in quality education. Nonetheless, it does not include measurement mechanisms nor intermediate goals. It does not count on a fixed budget, but operates with funds subject to approval, with no guarantee for continuity. Educational strategies are traditional and controlled centrally by a specific unit, restraining innovation. It has a pertinent but insufficient computing and networking infrastructure. Having the financial system as it is, it cannot commit to long-term projects. It does not provide institutional support for educational technologies.

Faculty training needs are not formally identified, but a program supported by existing faculty members is in place. Software tool availability is limited to what exists in the laboratories, and there are no commercial agreements with vendors.

As for the integration of ICT in the curricula, the university does not have any initiative to do so. Furthermore, the only technologies it has available are a digital library and a media classroom. Collaboration supported by technology is absent. Administrative processes are moderately automated and run well enough.

\subsubsection{Mexican University 4}

With over 90,000 students, this private institution is one of the pioneers in education innovation, and in the use of ICTs for improving the teaching and learning processes. Its current educational model is strong in innovative didactic approaches, as well as in the intense use of ICTs. This is recognized 
at all managerial levels, and an excellent infrastructure is in place, as well as the associated support services. Unlike its public counterparts, its students are financially strong, and most have at least two devices at home for their exclusive use. Many years ago, this university made it mandatory for students to acquire a laptop, or guarantee access to one, so that all courses could run in a blended learning environment, implemented in Blackboard, becoming this company's largest client worldwide. They are currently moving to Canvas. It also provides institutional incentives to faculty members for projects about innovation in education.

Faculty training programs are extensive, and the requirements depend on the path of each professor, since they can be categorized differently. Each professor has a whole program to undertake as a requirement to continue. Once this has been fulfilled, they need to take at least $40 \mathrm{~h}$ of training per year. A great proportion of the courses offered are related to ICTs. Each campus has an Educational Innovation Center, in charge of defining and designing the training offerings. ICTs and LKTs are extensively integrated into the curriculum to potentiate the learning process.

The use of ICTs certainly promotes interaction and collaboration. The university intensively promotes the development and use of educational resources, and it has one of the largest repositories as well. It takes advantage of learning analytics, since all the administrative and academic systems are integrated nationwide. Academic work groups are also supported by technology, provided that the university system has campuses distributed across the nation.

\subsection{Data Analysis}

Based on the rubric, numeric scores were assigned to each category and dimension, and to each university. The scores ranged from 1 to 5, 1 being the lowest level of maturity, named "absent", and 5 the highest level, named "consolidated". A comparative score graph is presented to illustrate the state of the universities in the study, as shown in Figure 2, and a gap analysis graph in Figure 3.

From Figure 2, it is clear that scores for Spanish universities rank higher on average than those of their Mexican counterparts, with the exception of the private one. Infrastructure and organizational technology do not seem to be a matter of concern. However, there is a clear variation in the level of usage of LKTs. On the other hand, Mexican universities show relatively low scores in ICTs and OCTs. It may be inferred that, regardless of the lack of base technology, there are initiatives to profit from LKTs that are widespread in their communities.

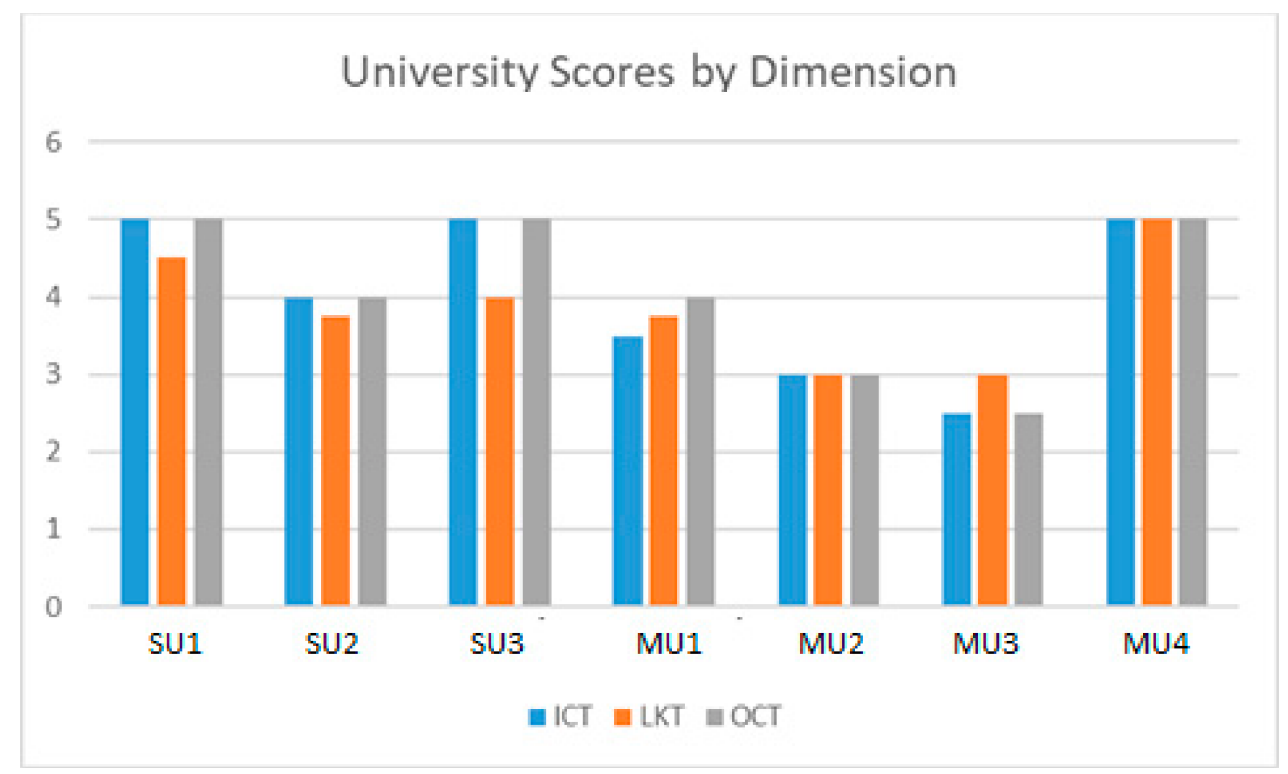

Figure 2. Scores by dimension and university. 


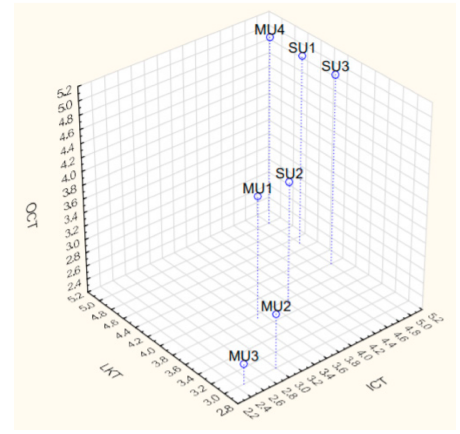

Figure 3. Dispersion chart of university scores in the three dimensions.

From the information provided in Figure 2, the least advanced situation seems to be that of MU3, and the best one for MU4. However, this does not reflect a good or bad result. It may be an indicator that a newly created university is using alternative ways of offering quality education, despite its administrative restrictions. The one thing that is certain is that the results are clearly polarized in Mexico.

Finally, a dispersion graph, shown in Figure 3, was created to visually map the maturity of each university in a three-dimensional field, and to provide an integrated view of the position of each institution overall.

The graphs shown allow for making a comparison regarding the selected items. Even when the responses show an established rubric result, and it could be thought that it is a qualitative approach, it is relevant to point out that the universities indicated clearly answered the same questions, which makes it possible to compare the state of each university. This provides an opportunity for identifying opportunity areas that may aid school administrators to put in place actions that improve their technological application to strengthen the educational process, with regard to all three dimensions.

\section{Discussion}

The assessment of the institutions presents very different panoramas in the different universities and, especially in Mexico (a country of great contrasts), there are very varied realities, even among the same public schools, which is why this section of the article will not be framed by a comparative analysis, but rather by the location of challenges, in general, to locate the opportunities within the framework of Sustainable Development Goal 4 and Society 5.0.

The results indicate that the incorporation of technologies in higher education, in the broadest sense (ICT, LKT and OCT), has meant a supposed digital transformation, some challenges (social, formative, political and economic) and "globalization" on the part of the universities that increasingly seek scenarios for all based on quality and equitable education $[7,8,28,30]$. The universities involved in this research have a strategic plan for the integration of ICT, linked to public policies in the local or national education system. These universities give faculties and higher institutions a certain amount of autonomy in planning, acquiring and responding to ICT needs. It can be seen that the large universities have ICT support units for educational purposes. In Spain, the three universities have a very similar model and are now involved in inter-institutional projects [17]. On the contrary, in Mexico, and depending on the region and state, there are very considerable variations according to the nature of each university $[19,20]$. The results also indicate that the interoperability and efficiency of the administrative systems, the use of networks and the implementation of virtual platforms not only help the technological dimension, but also the pedagogical and organizational dimensions of the institutions.

The assessment presented by the seven universities leads us to reflect on the training and infrastructure that higher education institutions receive, and provides us with insights to redesign an increasingly socio-economic, sustainable and inclusive system, driven by three dimensions: technological, pedagogical and organizational. The combination of these three dimensions, in physical 
and cyber physical spaces, gives rise to an approach to technologies based on empowerment and participation (EPT). This set of scenarios helps us move from the fourth industrial revolution to so-called Society 5.0, the "super-intelligent" society, with the aim of adapting to the challenges and needs of the moment, and reformulating the relationship between technologies and society and the relationship between individuals and society mediated by technologies [31], where the fingerprints of these relationships remain [32].

In relation to the teaching-learning processes, the importance of the pedagogical dimension, teacher training and the acquisition of certain digital skills are clearly considered in all seven universities as elements for quality education. In Mexico, this is observed in the existing plans for updating disciplinary and technological knowledge, which vary only according to the resources available to support development and training programs. However, in Spain, the results point to the use of technologies at the initial levels, and the need to acquire digital competences in the various learning processes $[9,10,17,21]$.

However. It is clear that all institutions, regardless of their location, seek the same transformational objectives, that is, to increase their ability to profit from a rich implementation of ICTs, LKTs and OCTs. Nonetheless, the results suggest that the ability to reach such an objective is subject to severe contextual restrictions. Universities in Spain, and their community members, have enough resources to make it happen. Their level of maturity seems to be a function of culture, priorities and will. Thus, the apparent lag for SU2 is not a function of financial or infrastructure restrictions, but a result of a culture that supports the voluntary use of technologies, rather than imposing a university-wide policy enforcement.

Differences among Spanish universities do not seem to be significant, compared to their Mexican public counterparts. The latter seem to be severely constrained by lack of funding, or financial allotment procedures that do not prioritize spending on ICTs nor allow for the continuity of an ICT implementation and display project. This is further negatively affected by the lack of infrastructure in the country, and the precarious financial situation of their community members. A recent analysis, done by MU1 due to the COVID-19 pandemic, determined that close to $20 \%$ of its population (that is, approximately 72,000 students) lack either connectivity or a computing device at home. This is a major challenge when planning on blended or online environments that require alternative measures. Furthermore, other universities are located in more rural environments, making it reasonable to assume the situation may be worse.

The particular case of the main private university in Mexico (MU4) that is included in the study, and that appears to have a perfect score, should also be treated carefully. Even when all standards are met, as a result of a well-planned education and technology strategy, there is no perfect final product, nor a guarantee that an appropriate approximation to quality education has been reached. There is a need to clearly analyze the impact of applying technologies on the students, so that real knowledge and skill development can be assessed.

The relevance of access to ICTs and their application for pedagogical purposes is not questionable to foster a quality education and promote the development of the knowledge society. However, it is also noticeable that attaining such goals can be challenging, especially in environments and communities that face harsh economic conditions and severe infrastructure shortages. This is in addition to potential cultural barriers, and administrative obstacles, that result from unfavorable governmental policies, in agreement with SDG 4 [1]. Finding creative ways to overcome such challenges is paramount for those disadvantaged educational institutions so that they can evolve and reduce the digital gap. The problem becomes more complex when it is understood that it spans beyond the institutional domain, being affected by social and economic constraints.

\section{Conclusions}

The integration and use of technologies in education systems in general, and in teaching processes in particular, is not happening as the digital and 2030 agendas suggest, as research 
shows. Infrastructure, digital equipment, training, organization and management of technologies, together with the non-acquisition of certain digital technologies, are key elements that persist in the society of the fourth industrial revolution. This phenomenon, coined by Schwab [6], affects all spheres of life. Therefore, the education system is not immune to it, and it is considered necessary to train more interconnected, globalized people in flexible and changing contexts, with skills and competences to adapt to society in the digital age and, in turn, ensure quality and inclusive education. To create a sustainable society and contribute to a true digital transformation, people need knowledge and skills to achieve this under an education for sustainable development approach. In this sense, higher education, as has been pointed out in our research, requires educational, technological and political changes with an ethical commitment to reach the agreements of Agenda $2030[20,23]$.

Although there have been extensive studies on the integration of ICT in higher education, most of them address technologies from a technological rather than a pedagogical and organizational point of view. One of the strengths of this work is that the three perspectives-technological, pedagogical and organizational—intersect, as they are inseparable and necessary to consider and evolve the level of ICT integration to a higher level of maturity. Higher education institutions have specificities that should not be ignored. These specificities become even more important when considering the great variety of objectives and cultures that exist in the universe of educational institutions.

After the assessment presented here, the challenge of COVID-19 arrived at the universities. The doubts about the possible adoption of new technologies in the training processes in educational institutions were automatically dispelled as a result of the new reality that conditioned people to establish interactions remotely. People who resisted the use of new technological supports (mobile phones, tablets, computers, platforms, online education), advances in technology (artificial intelligence, robotics, the Internet of Things, cloud computing, etc.) and who were unaware of didactic strategies mediated by technologies from educational software saw how the barriers that prevented this approach quickly vanished to adapt to the new educational panorama, as a result of the effects of COVID-19.

The phrase popularized in the United States, thinking outside the box/out of the box, or the conceptualization of de Bono's lateral thinking [33], acquired weight in the face of the need to seek solutions, without following traditional logical guidelines, and to acquire alternative instances of resolution by avoiding preconceived ideas. The challenge now is to capitalize on this forced reality, to encourage the processes of adoption of new technologies, but the focus is not only the acquisition of the technological infrastructure, but is, fundamentally, the training of teachers, administrators and directors so that the remote act of communication is transformed into educational teaching strategies. This will result in collaboration networks that better fit the needs of the digital society.

Evidently, this study has plenty of elements that can be improved and need further elaboration. First, SDG 4 implies much more than technological applications. It includes issues like gender equality and empowerment, lifelong learning opportunities, innovation promotion and global partnerships. These issues should be addressed to complement the findings. Additionally, the analysis should be extended to more individuals for each institution, and more institutions in several countries to examine commonalities and differences that could help in planning a digital education agenda. Finally, the instrument can always be modified and improved. All these elements represent opportunities for future research. This paper is an invitation to continue studying the relationship between the dimensions, with a view to reducing the digital gap to support training in universities and to meet the challenges of the Society 5.0.

Author Contributions: Conceptualization, G.R.-A. and S.M.-P.; Formal analysis, M.S.R.-M., G.R.-A., S.M.-P. and E.L.-C.; Funding acquisition, M.S.R.-M., G.R.-A. and E.L.-C.; Investigation, G.R.-A. and S.M.-P.; Methodology, G.R.-A.; Project administration, G.R.-A.; Validation, M.S.R.-M., G.R.-A., S.M.-P. and E.L.-C.; Writing-original draft, M.S.R.-M., G.R.-A., S.M.-P. and E.L.-C.; Writing-review and editing, M.S.R.-M., G.R.-A., S.M.-P. and E.L.-C. All authors have read and agreed to the published version of the manuscript.

Funding: The authors would like to acknowledge the financial support of Fideicomiso SEP-UNAM and Writing Lab, TecLabs, Tecnologico de Monterrey, Mexico, in the production of this work. 
Acknowledgments: To the teachers and managers and institutions involved.

Conflicts of Interest: The authors declare no conflict of interest.

\section{References}

1. Global University Network for Innovation. Approaches to SDG 17 Partnerships for the Sustainable Development Goals (SDGs); GUNi: Barcelona, Spain, 2018.

2. General Assembly. Resolution Adopted by the General Assembly on 6 July 2017. 71/313. Work of the Statistical Commission Pertaining to the 2030 Agenda for Sustainable Development; United Nation: New York, NY, USA, 2017; pp. 1-25.

3. UNESCO. Educación 2030. Declaración Incheon; UNESCO: París, France, 2016.

4. Elfert, M. Lifelong learning in Sustainable Development Goal 4: What does it mean for UNESCO's rights-based approach to adult learning and education? Int. Rev. Educ. 2019, 65, 537-556. [CrossRef]

5. European Commission/EACEA/Eurydice. Teaching Careers in Europe: Access, Progression and Support. Eurydice Report; Publications Office of the European Union: Luxembourg, 2018. [CrossRef]

6. Keidanren. Society 5.0. Co-Creating the Future; Keidanren Policy \& Action: Tokyo, Japan, 2018.

7. Schwab, K. The Fourth Industrial Revolution; Crown Business: New York, NY, USA, 2016.

8. Joyanes, L. Industria 4.0. La Cuarta Revolución Industrial; Alfaomega-Marcombo: Mexico City, Mexico, 2018.

9. Sala, A.; Punie, Y.; Garkov, V.; Cabrera Giraldez, M. LifeComp: The European Framework for Personal, Social and Learning to Learn Key Competence; Publications Office of the European Union: Luxembourg, 2020; JRC120911. [CrossRef]

10. European Commission/EACEA/Eurydice. Digital Education at School in Europe; Eurydice Report; Publications Office of the European Union: Luxembourg, 2019. [CrossRef]

11. Romero-Rodríguez, J.M.; Ramírez-Montoya, M.S.; Aznar-Díaz, I.; Hinojo-Lucena, J. Social appropriation of knowledge as a key factor for local development and open Innovation: A Systematic Review. J. Open Innov. Technol. Mark. Complex. 2020, 6, 44. [CrossRef]

12. Brown, M.; McCormack, M.; Reeves, J.; Brooks, C.; Grajek, S.; Alexander, B.; Bali, M.; Bulger, S.R.; Dark, S.; Engelbert, N.; et al. 2020 EDUCAUSE Horizon Report, Teaching and Learning Edition; EDUCAUSE: Louisville, CO, USA, 2020.

13. Melki, A.; Nicolas, M.; Khairallah, M.; Adra, O. Information and communications technology use as a catalyst for the professional development: Perceptions of tertiary level faculty. Int. J. Educ. Dev. Using Inf. Commun. Technol. (IJEDICT) 2017, 13, 128-144.

14. Ramírez-Montoya, M.S.; Lugo-Ocando, J. Systematic review of mixed methods in the framework of educational innovation. Comunicar 2020, 65, 9-20. [CrossRef]

15. Romero-Rodríguez, L.M.; Ramírez-Montoya, M.S.; Valenzuela, J.R. Incidence of digital competences in the completion rates of MOOCs. Case study on Energy Sustainability courses. IEEE Trans. Educ. 2020, 1-7. [CrossRef]

16. OECD. OECD Skills Strategy 2019: Skills to Shape a Better Future; OECD Publishing: Paris, France, 2019. [CrossRef]

17. Romero-Rodríguez, L.M.; Ramírez-Montoya, M.S.; Aguaded, I. Determining Factors in MOOCs Completion Rates: Application Test in Energy Sustainability Courses. Sustainability 2020, 12, 2893. [CrossRef]

18. European Comission. Digital Education Action Plan (2018-2020); Publications Office of the European Union: Luxembourg, 2018.

19. Ithurburu. Políticas Digitales en Los Sistemas Educativos de América Latina (2013-2018). Estado del Arte de la Investigación a la Politica [Digital Policies in Latin American Education Systems (2013-2018). State of the Art from Research to Policy]; IIPE-UNESCO: Buenos Aires, Argentina, 2019.

20. Maldonado, C.; Marinho, M.L.; Robles, C. Inclusión y cohesión en el marco de la Agenda 2030 para el Desarrollo Sostenible: Claves para un desarrollo social inclusivo en América Latina [Inclusion and Cohesion in the Framework of the Agenda 2030 for Sustainable Development: Keys to Inclusive Social Development in Latin America]; Comisión Económica para América Latina y el Caribe (CEPAL): Santiago, Chile, 2020.

21. Alonso-García, S.; Aznar-Díaz, I.; Cáceres-Reche, M.P.; Trujillo-Torres, J.M.; Romero-Rodríguez, J.M. Systematic Review of Good Teaching Practices with ICT in Spanish Higher Education. Trends and Challenges for Sustainability. Sustainability 2019, 11, 7150. [CrossRef] 
22. Ramírez-Montoya, M.S. Challenges for Open Education with Educational Innovation: A Systematic Literature Review. Sustainability 2020, 12, 7053. [CrossRef]

23. UNESCO. Goal Dialogue on ICT and Education Innovation-Towards Sustainable Development Goal for Education (SDG4); Russian Federation: Moscow, Russia, 2019.

24. Institute of Education Technology. Innovating Pedagogy 2020. Exploring New Forms of Teaching, Learning and Assessment, to Guide Educators and Policymakers; The Open University: London, UK, 2020.

25. The Higher Education Sustainability Initiative (HESI). Raising and Mapping Awareness of the Global Goals. Report to the High.-Level Political Forum on Sustainable Development; United Nation: New York, NY, USA, 2019.

26. OECD. How's Life in the Digital Age? Opportunities and Risks of the Digital Transformation for People's Well-Being; OECD Publishing: Paris, France, 2019. [CrossRef]

27. Filho, W.L.; Jim, Y.C.; Londero, L.; Veiga, L.; Miranda, U.; Caeiro, S.; Rejane da Rosa, L. Identifying and overcoming obstacles to the implementation of sustainable development at universities. J. Integr. Environ. Sci. 2017, 14, 93-108. [CrossRef]

28. Global University Network for Innovation. Humanities and Higher Education: Synergies between Science, Technology and Humanities; Higher Education in the World 7; GUNi: Barcelona, Spain, 2019.

29. Kriscautzky-Laxague, M.; Martínez-Sánchez, M.E.; Rodríguez-Abitia, G. Desarrollo de un Instrumento para Medir el Aprovechamiento de las TIC y las TAC en las Instituciones de Educación Superior` [Development of an Instrument to Measure ICT and LKT Profiting in Higher Education Institutions]. In Horizonte Educativo: Una Mirada al Futuro de las Profesiones y la Educación (Volume 1); Chan-Núñez, M.E., Mateos-Morfín, L.R., Eds.; Sistema de Educación Virtual de la Universidad de Guadalajara: Guadalajara, Mexico, 2019; pp. $227-252$.

30. UNESCO. UNESCO Science Report: Towards 2030; UNESCO Publishing: Paris, France, 2015.

31. Hitachi-UTokyo Laboratory (H-UTokyo Lab). Society 5.0. A People-Centric Super-Smart Society; Springer: Singapore, 2020. [CrossRef]

32. Buitrago-Ropero, M.E.; Ramírez-Montoya, M.S.; Chiappe Laverde, A. Digital footprints (2005-2019): A systematic mapping of studies in education. Interact. Learn. Environ. 2020. [CrossRef]

33. De Bono, E.; Zimbalist, E. Lateral Thinking; Penguin: London, UK, 1979; pp. 1-32.

Publisher's Note: MDPI stays neutral with regard to jurisdictional claims in published maps and institutional affiliations.

(C) 2020 by the authors. Licensee MDPI, Basel, Switzerland. This article is an open access article distributed under the terms and conditions of the Creative Commons Attribution (CC BY) license (http://creativecommons.org/licenses/by/4.0/). 